\title{
Exploration on Animation Teaching in Universities under the Mode of Industry-University-Research Cooperation
}

\author{
Wang Jin \\ Zaozhuang University \\ Zaozhuang, Shandong
}

\begin{abstract}
The combination of Industry-University-Research (IUR) and animation provides favorable conditions for universities and scientific research institutions to cultivate innovative talents, strengthens the core competitiveness of animation enterprises, and enables universities, enterprises and scientific research institutions to realize mutual benefit and mutual assistance, thereby achieving a virtuous circle of development. This paper analyzes the ways to promote cooperation between the animation industry and IUR based on the government's guidance on the IUR model of the animation industry and the talent training mechanism between universities and enterprises. It is of great significance to reform the training mode of animation professionals in universities, meet the requirements of animation enterprises for talents, and promote the development of cultural and creative industries.
\end{abstract}

Keywords-Animation;Industry-University-Research; Teaching; Industry; Culture Creativity

\section{INTRODUCTION}

With the rapid development of modern science and technology, and culture and art, people's both material life and cultural life have been deeply affected. The culture and creative industries dominated by animation, comics, digital media art and game are really hot and popular. Nowadays, those majors of artistic creativity including animation, game and digital media art are warming up rapidly in most colleges and universities in China. The development of cultural and creative teaching in colleges and universities has attracted wide attention from all sectors of society. As animation industry develops rapidly, the demand for animation talents is increasing, and the requirements for animation talents in skills and theory are being raised. The colleges and universities become the main force to cultivate animation talents, and the training mode integrating animation education with industry has gradually emerged. The IUR platform of animation offers knowledge reserve and practical basis for animation teaching in colleges and universities. It is a new animation education mode that effectively converts professional knowledge into productivity in the process of teaching, and combines theory with practice.

\section{PRESENT Training Mode For ANIMATION TALENTS IN COLLEGES AND UNIVERSITIES AND ITS DISADVANTAGES}

Animation teaching started relatively late in China. It is an interdisciplinary discipline which integrates art, science and technology, humanity and so on. Its classifications of courses are very extensive. The courses offered by colleges and universities for animation major mainly include introduction to animation, history of world animation, animated cartoon sketch, fundamental of 2D animation, comic strip, stop-motion animation, audiovisual language of animation, animation sublens design, 3D animation production, etc. The teaching of animation courses pays equal attention to animation theory and practical operation. Through the operation and demonstration of courseware and cases, teachers can intuitively cultivate students' professional learning. Nowadays, higher requests are brought forward to the teaching and cultivation of animation professionals [1]. At present, the animation education in most colleges and universities still stays on the basic theory, and lacks exercises on skills and practice. The training programs of animation professionals and curriculum are not perfect enough. So, students are short of ability of practical operation, and unable to cope with the tests from enterprises and markets, which results in a great discrepancy between the animation talents trained by colleges and universities and the demand for the market and cultural and creative enterprises. After graduation, students majoring in animation work in the cultural and creative enterprises. But if they are not qualified for the production process with high professional and practical qualifications as required, they have to learn twice in the enterprises, which sharply reduces the production efficiency of animation enterprises. According to the statistics of the departments concerned, it has been reported that animation, game and other majors of artistic creativity are red sign university majors with high risk and high unemployment since 2001. It indicates that the education and teaching of animation in colleges and universities urgently need a reform. The colleges and universities should change the traditional, single, outdated and theoretical teaching methods, and replace it with innovative and efficient ones. Focusing on students, subject teachers should encourage students and guide their interests and hobbies, so as to arouse their interest in learning and develop their potential for artistic creation [2]. Meanwhile, under the guidance of the market and animation enterprises, the 
colleges and universities should arrange the major setup and curriculum system of animation comprehensively and reasonably. Pay more attention to improving students' professional skills and ability of practical operation, in order to give them a wide access to the regulations of relevant industries and enable them to deeply understand the demand of animation enterprises for talents before graduation. Faced with this problem, the colleges and universities need to cooperate with some cultural and creative enterprises, and try the best to study and explore a new mode of training animation professionals.

\section{THE MODE OF INTEGRATION OF ANIMATION AND IUR}

The IUR integration of animation refers to the organic combination of animation teaching, scientific research and production. It is the outcome of the rapid development of cultural and creative enterprises in the background of cultural development. Internationally, the IUR integration is also called cooperative education [3]. Such a cooperative education mode provides necessary innovative and applied talents for the development of contemporary society and enterprises. In the process of cultivating animation talents in colleges and universities, the culture of enterprises should be associated with the establishment of experimental bases, and the independent research strategies of scientific research units should be incorporated, then a strategical mode forms. The mode supplies basic and professional knowledge and a very necessary practice foundation for animation education and teaching in colleges and universities. This mode of training talents can not only bring cultural and creative talents with more practical and reliable professional skills for cultural and creative enterprises and the society, but also make full use of the resources of animation education in colleges and universities. It allows the scientific research achievements of colleges and universities to turn into productivity efficiently and quickly, thereby achieves a win-win situation between universities and cultural and creative enterprises [4]. The IUR integration is a new education mode that transforms rigid knowledge into advanced productivity when teaching, and integrates teaching with scientific research, theory with practice. It provides necessary intellectual support and an access to personnel training for the development of animation and other cultural industries.

The IUR cooperation of animation can not only provide necessary professionals for animation enterprises, but also make full use of the educational resources of colleges and universities, so that the innovative, scientific and educational achievements of animation products can be more quickly and easily transformed into social productivity, and universities and animation enterprises can realize win-win cooperation. Constructing an innovative service platform for animation research and development is a very important way to facilitate the management-oriented local governments to become the service-oriented one. The famous Canton Fair and CHTF in Shenzhen are both successful examples that local governments lead enterprises, universities and scientific research institutions to participate in scientific and technological exchanges and economic cooperation [5]. Local governments at all levels ought to actively and effectively build a public information service management platform for the development of animation industry, play a role as a bridge between local animation societies and associations, and correctly guide them. In this way, local governments can contribute to effective and scientific connection between universities and animation enterprises. Local governments should also transform the advantages of talents, scientific research and intelligence in universities and scientific research institutions into the economic and industrial advantages of enterprises, so as to enable animation enterprises to fully rely on and make use of external resources and complete their own innovation, finally we can quickly adjust the structure of animation industry.

\section{THE IMPORTANCE OF THE IUR COOPERATION MODE FOR THE DEVELOPMENT OF ANIMATION EDUCATION}

In the education of animation major in colleges and universities, teaching is one of the basic functions of colleges and universities, and plays an important role in fulfilling the propose for cultivating talents. The contents of courses convey significant information in the teaching and learning process. Only follow the information and technology age and keep pace with the times, can the education of colleges and universities be full of vitality. When the animation education in colleges and universities prosperously develops, we also notice the hidden crisis behind the bubbles of great prosperity. As the main body to teach courses of animation major, the teachers in colleges and universities are particularly important in teaching. The professional theoretical level and skill level of the teachers directly affect the efficiency and quality of education. A teacher of animation major should actively study the corresponding professional theories. Besides, he should participate in the practice of animation creation and accumulate creative experience in practice, so as to improve the teaching level. However, many problems, such as the lack of teachers, professional teaching materials, high teaching level and experience, have seriously restricted and affected the development of animation education in colleges and universities. In most colleges and universities, the teaching contents concentrate upon comic strip, 3D film and television animation, game illustration and the like, so the students taught in this way just have single skills and a narrow range of professional knowledge. Today, the animation talents trained by colleges and universities can't meet the demand of the society and enterprises, and it is difficult for the graduates to find a job. On the other hand, animation companies can not recruit the talents they want, so they have to train by themselves, which results in a waste of time and money and thus lowers the production quality. There exists a great discrepancy on the development of animation education and animation industry between China and America or Japan. In general, China is at a relatively low level in this regard. The shortage of animation talents and the outdated, single training mode of professional talents in colleges and universities have severely constrained the rapid development of domestic animation industry. It is imperative to implement a reform and cooperation between the teaching mechanism of animation education in universities and the operation mechanism of enterprises. 


\section{THE MEASURES FOR THE COOPERATION OF IUR AND ANIMATION}

The IUR cooperation of animation can achieve a win-win situation between animation enterprises and universities. This paper analyzes some factors that restrict the IUR integration of animation, and puts forward the following suggestions and measures.

\section{A. Government's Support and Guidance for the IUR of Animation}

The government should fully play a role in macro guidance and promotion, support the IUR cooperation of animation, and actively plan the animation industry and build an innovative platform for animation research and development. The government needs to make plans to promote the development of the animation industry, provide support and incentives for enterprises, and stimulate the IUR integration to develop. Additionally, the government should set up basic research funds for talents specially and strive to guide the animation IUR towards a market-oriented road. In this way, the local can obtain a forceful guarantee to establish the innovative service platform for the animation IUR. In recent years, both the central and local governments have successively published a series of tax-free policies, in order to increase the support for animation industry. The governments can set up special funds for local animation enterprises to help them develop freely and flexibly.

\section{B. Establish the Talent Flow Mechanism}

The colleges and universities should encourage teachers of animation major to cooperate with local animation enterprises and animation industry bases, and lay the emphasis of scientific research on the development of services and professional skills of animation enterprises. Moreover, teachers are supposed to commit corresponding professional issues of animation major and scientifically motivate students to create animation works.

Once the works are adopted by the market, enterprises, or public institutions, the schools should reward the students financially. As the circumstances may require, the schools had better give some allowances and rewards to the professional talents who have made outstanding contributions to animation major. Thereby, the organic coordination of mechanism and the animation IUR is achieved.

\section{Attach Importance to the Talent Training Mechanism Between Universities and Enterprises}

The colleges and universities should organize their students to probe into the problems about theory and technology they encounter in teaching and learning, real production and scientific research. The training mode that universities and enterprises cooperate to cultivate talents is characterized by the direct link between students' practice and enterprises. On the one hand, it meets the needs of enterprises for animation talents; on the other hand, it improves students' operational skills and adaptability to their positions. It helps to generate a suitable talents training mode for enterprises and universities. So, students can better absorb the influence of the animation enterprise environment and improve their skills. And enterprises can also shorten the training time of employees and improve their operating efficiency. In a word, this mode greatly reduces the cost and time of talents training for enterprises. If students are directly integrated into the enterprises, the enterprises can have a targeted training and teaching, then cultivate the animation professionals they need, which certainly ensures the enterprises potential talents. In the meantime, students can also go deep into the enterprises to receive training and learning, technically trained and instructed by the professional in the enterprises, even though they haven't graduated from colleges or universities. By means of professional training and practice, students can learn the professional skills and knowledge that the enterprises really need, and improve their adaptive capacities for work [6], which lays a solid foundation for students to be qualified for their work after graduation in the future. Therefore, from this point of view, the talents training mode that connects enterprises directly with universities achieves a win-win situation among enterprises, universities and students. Animation enterprises and animation major cooperate deeply with each other. Freshmen and sophomores learn the theoretical knowledge of art majors and basic skills of animation major. In the third year in school, colleges and universities should organize students to practice and train skills in the cooperative animation enterprises. Students can personally feel the cultural atmosphere of the enterprises, and be infused with the cultural edification there. The pre-job training improves students' professional skills and helps them with the full combination of theory and practice.

\section{CONCLUSION}

IUR is the outcome of the integration of contemporary enterprises and culture. It provides an innovative, practical, efficient and intelligent mode of teaching and training talents for the development of contemporary society, and also provides favorable conditions for the cultivation of innovative talents for universities and research institutions. The IUR integration of animation can effectively integrate the resources of universities, animation enterprises and research institutes for the common goals and interests, and achieve the cooperation that is mutually beneficial. Thereby, it accelerates the development of cultural and creative industries.

\section{REFERENCES}

[1] Zhang $\mathrm{Xi}$, Zhang Huilin. A Brief History of Animation Industry at Home and Abroad [M]. China Ocean Press, 2014. (In Chinese)

[2] Liu Bin. Research on the Policy and Innovation of China's Animation Industry [M]. Communication University of China Press, 2016. (In Chinese)

[3] Tan Mingxiang, Tu Xianzhi, Li Leiming. Educational Research and Teaching Practice of Animation Major [M]. JiNan University Press, 2017. (In Chinese)

[4] Chen Shujiao, Dou Wei. Research on the Structure of Animation Industry Chain: Taking the Animation Industry in Beijing as an Example [M]. China Social Sciences Press, 2013. (In Chinese)

[5] Geng Rui. Research on Organization Optimization of Chinese Animation Industry [M]. Xue Xi Press, 2014. (In Chinese)

[6] Zhang Huiling. Animation +: Research on Transformation and Upgrading of China's Film and Television Animation Industry [M]. Social Sciences Academic Press, 2016. (In Chinese) 